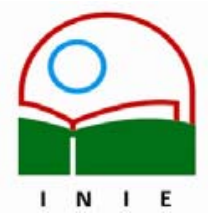

Universidad de Costa Rica

Facultad de Educación

Instituto de Investigación en Educación

ACTUALIDADES INVESTIGATIVAS EN EDUCACION

\title{
ACREDITACIÓN: \\ ¿CALIDAD O INSTRUMENTO DE LEGITIMACIÓN PARA LA EDUCACIÓN SUPERIOR?
}

Elsiana Guido Guido ${ }^{1}$

\begin{abstract}
Resumen: El presente artículo analiza el surgimiento de la acreditación de carreras y de programas en Costa Rica en el marco de una redefinición del sistema educativo superior dentro de la coexistencia de dos estilos de desarrollo. Se contextualiza a qué responde el surgimiento de la acreditación en Costa Rica., cuál es su vinculación con las nuevas tendencias en el estilo de desarrollo nacional pos ajuste y cuál es su función en la configuración del sistema de educación superior costarricense. Según la autora, la acreditación responde directamente a la lógica de un Estado que delega, en otras instancias, su rol ejecutor e interventor directo, mientras que las fuerzas del mercado se fortalecen y definen aspectos importantes de la organización y oferta del sistema de educación superior.
\end{abstract}

\section{Palabras clave: ACREDITACIÓN/ EDUCACIÓN SUPERIOR/ ESTILO DE DESARROLLO/}

Abstract: This article analyzes the arising of accreditation of careers and programs in Costa Rica on the frame of the Higher education system re-definition, and in a context where two development styles coexist. It is contextualize what does the arise of accreditation in Costa Rica respond to, which is its link to the tendencies of national development style, and which is its function in the configuration of the Costa Rican higher education system. According to the author, the accreditation responds directly to the logic of a State that delegates its roll as executive and direct supervisory body to other institutions while the national forces strengthen, and define important aspects of the organization and supply of the higher education system.

Key words: ACCREDITATION/ HIGHER EDUCATION/ STYLE OF DEVELOPMENT/

\section{Presentación ${ }^{2}$}

El surgimiento del debate y la praxis de la acreditación de las carreras universitarias, se han convertido en uno de los temas más polémicos sobre el presente y futuro de la educación superior costarricense. Para algunas personas, la acreditación vendría a llenar un vacío respecto a los mecanismos para controlar y regular la calidad de la educación superior,

\footnotetext{
1 Politóloga y administradora de programas educativos no formales, de la Universidad de Costa Rica. Investigadora del Departamento de Investigación y Evaluación Académica del Centro de Evaluación Académica de la Universidad de Costa Rica. Investigadora en el Consejo Centroamericano de Acreditación de la Educación Superior. Estudios avanzados en Pedagogía Social, Ciencias Políticas y Sociología en la. Universidad Johannes Gutenberg- Alemania.
}

Correo electrónico: eguido@cariari.ucr.ac.cr

Artículo recibido: 14 de julio, 2005

Aprobado: 19 de setiembre, 2005

\footnotetext{
${ }^{2}$ El presente artículo se basa en algunas de las conclusiones de la investigación La Acreditación: Los desafíos de la Educación Superior Costarricense en un nuevo estilo de desarrollo; elaborada en el marco del Proyecto Camina-Costa Rica. 2002. Centro de Evaluación Académica. Universidad de Costa Rica. CONARE. La investigación fue realizada por la autora de este artículo y el politólogo Hárold Villegas, profesor universitario.
} 
particularmente ante el aumento desproporcionado de la oferta superior privada; para otras, la acreditación significaría un instrumento para legitimar y ocultar la pésima calidad de algunas instituciones de educación privada, al homologarse carreras en el mismo nivel de las carreras impartidas en la educación superior estatal. De esta manera se ubican a las universidades estatales en el mismo "pedestal" de algunas de las cuestionadas instituciones privadas de educación superior. Desde esta perspectiva, la acreditación sería un instrumento del negocio o de la iniciativa privada.

No obstante ambas tesis, el análisis del surgimiento de la acreditación de carreras universitarias en Costa Rica se convierte en un proceso más complejo de lo que podríamos esperar. Esto es así, en parte, por la trascendencia socio-económica del contexto en que empieza a ser necesaria la acreditación, y en el que converge una serie de variables que limitan una opción de análisis o explicación reduccionista.

Es así como el análisis del tema debería situarse en dos niveles diferentes: el primero, las razones objetivas del surgimiento de la acreditación en Costa Rica. El segundo, los efectos de la acreditación en la configuración del sistema de la educación superior costarricense. En el presente artículo se desarrolla el primer nivel mencionado y se pretende aportar algunos elementos que contribuyan al análisis del segundo nivel en lo que se refiere a la reconfiguración de todo el sistema de educación superior, tanto estatal, como privado. Para esto, se plantean algunas interrogantes, que pueden contribuir a futuras investigaciones, sobre la práctica de la acreditación desarrollada en el país y sus efectos sobre el mejoramiento de la calidad.

El objetivo del artículo se enfoca en analizar el origen de la acreditación en Costa Rica, en el contexto de un nuevo estilo de desarrollo, y sus posibles implicaciones para el sistema de educación superior estatal y privado.

En un esfuerzo por dar respuesta a estas inquietudes, se plantean las siguientes interrogantes:

- ¿A qué responde el surgimiento de la acreditación en Costa Rica? ¿Cuál es su vinculación con las nuevas tendencias en el estilo de desarrollo nacional posterior al 
ajuste? ¿Cuál es su función en la configuración del sistema de la educación superior costarricense?

\section{Cambios en la concepción del Estado}

\subsection{Estilo de desarrollo}

Los cambios en el ámbito de la educación superior deben analizarse dentro del contexto de reconfiguración del Estado costarricense, principalmente, en sus funciones económicas y sociales. Como no puede afirmarse que el Estado ha pasado a manos privadas la totalidad de sus tareas, se habla en este sentido de un tránsito inconcluso de un Estado intervencionista a un Estado regulador. Con esta connotación, se hace referencia a la coexistencia actual de rasgos pertenecientes a diferentes estilos de desarrollo. (Proyecto Estado de la Nación, Informe 10, 2004, p.155)

El estilo de desarrollo se refiere aquí, siguiendo los planteamientos de Jorge Rovira Mas, a la forma concreta como se mueve una sociedad en el transcurso de un período histórico particular. Se refiere al resultado social y político de la interacción de las alternativas propuestas por los diversos grupos sociales. Según lo anterior, el estilo de desarrollo:

no es el fruto únicamente [...] de los grupos sociales que patrocinan una estrategia de desarrollo específica y por completo hegemónica. Constituye más bien el fruto que se va decantando (a manera de valores que se difunden y de distintas prácticas que cobran vida institucional) de la interacción entre distintas estrategias, proyectos políticos y planteos en defensa de intereses sectoriales, los que son promovidos por grupos sociales que cuentan con recursos de poder con peso diferenciado en la escena política. (Rovira, 1995, pp. 5-6)

Estas estrategias y proyectos diversos son promovidos por grupos sociales que cuentan con recursos de poder con un nivel diferenciado en la escena política y que conllevan una ideología capaz de sustentar ese nuevo proyecto de desarrollo. En este sentido, hay varias opciones de desarrollo posibles; la que se impone no necesariamente constituye la más conveniente, sino "la viable" en ciertas condiciones históricas específicas. 


\subsection{De la crisis al camino de un nuevo estilo de desarrollo}

En los inicios de la década de los ochenta el país se sumerge en una crisis económica sin precedentes, desde la acontecida durante la gran depresión de los años treinta, producto de una serie de desequilibrios internos, agravados por el impacto de variaciones en el entorno internacional. Esta crisis pone en entredicho el estilo de desarrollo basado en la industria sustitutiva de importaciones (predominante en Costa Rica desde la década del 50 del siglo pasado), facilitando la irrupción de las primeras iniciativas y políticas que van decantando una nueva concepción sobre los mecanismos y estrategias para lograr el desarrollo.

El debate actual sobre el concepto de desarrollo es muy amplio y complejo a la vez. Se rescata la conceptualización del Programa de las Naciones para el Desarrollo en su informe de 1994, adoptada por el Proyecto Estado de la Nación, la cual trasciende lo meramente económico. En esta definición el concepto de desarrollo se amplía al de desarrollo humano sostenible, el cual se conforma como

un proceso continuo e integral, que reúne componentes y dimensiones del desarrollo de las sociedades y de las personas, en los que resulta central la generación de capacidades y oportunidades de, por y para la gente, con las que la equidad se acreciente para las actuales y futuras generaciones. (Proyecto Estado de la Nación Informe 8, 2002, p. 40)

Por otra parte, el Proyecto Estado de la Nación en Desarrollo Humano Sostenible, en su octavo informe, contextualiza el concepto al considerar que:

El desarrollo humano sostenible tiene un componente histórico, pues sus componentes, dimensiones y desafíos sufren una evolución distinta en cada sociedad, así como lo hacen las expectativas de la gente y las metas de referencia localizables en otros países. (2002, p. 40)

Es entonces en este período crítico de los años ochenta cuando se plantea la redefinición de la estructura productiva y de las funciones históricas del Estado, con consecuencias directas, particularmente, sobre el gasto y la inversión social. 
En el caso de Costa Rica, esta crisis económica colocó en tensión expresa dos estilos de desarrollo diferentes: por un lado, un estilo que privilegió un fuerte intervencionismo estatal en actividades económicas y productivas y una sistemática inversión social; y por otro lado, un nuevo estilo de desarrollo que va a privilegiar la liberalización económica, la privatización de "lo público" y la redefinición de las funciones económicas y sociales del Estado (fundamentalmente en términos de menor intervención y la búsqueda de mayor eficiencia en el uso de los recursos públicos).

El principal fundamento ideológico de este nuevo estilo de desarrollo será el pensamiento neoliberal y predominará desde la década de los ochenta, hasta nuestros días, sin que haya implicado un total abandono del intervencionismo estatal en la vida económica y social costarricense. El nuevo estilo de desarrollo que se va implementando en Costa Rica, a partir de estos años, no surge de manera espontánea o por la inevitabilidad del destino. Al contrario, es parte de proyectos políticos, estrategias y planteos, en defensa de ciertos intereses sectoriales promovidos, tanto en lo interno como en lo externo, con un impacto directo sobre la situación del país.

\subsection{Cuestionamiento a lo "público"}

Las características principales del estilo de desarrollo que se va perfilando en el país, corresponden a los planteamientos de organismos internacionales, tales como el Fondo Monetario Internacional (FMI) y el Banco Mundial (BM), y son también acordes con las políticas del Consenso de Washington.

Como bien lo apunta Joseph E. Stiglitz (2002, pp. 44-45), con el Consenso de Washington se sacralizaron las ideas a favor del libre mercado. Los instrumentos de política económica respondían, de esta manera, a los fallos encontrados en el papel del Estado como generador de empleo. Por este motivo, el FMI, el BM y el Tesoro de los Estados Unidos diseñaron las políticas que debían seguir los países subdesarrollados, destinadas a eliminar la excesiva intervención estatal en la economía.

Dentro de esto, el conjunto de políticas del Consenso de Washington definía el crecimiento económico como el parámetro para evaluar el desarrollo de un país (y el éxito de las políticas). La estrategia que proponía este grupo, fue centrar las políticas nacionales y las reformas en la estabilidad macroeconómica, la apertura y liberalización comercial y la 
reducción de la presencia del Estado. Posteriormente y, ante el deterioro de las condiciones de vida de amplios sectores de la población, incluyó dentro de su menú de políticas, las acciones de compensación social.

Las ideas pregonadas por los organismos internacionales y acogidas por diversos sectores sociales con acceso al poder político, además de la disciplina fiscal, el control de la inflación y la liberalización comercial, impulsaron la reducción de las funciones y el tamaño del Estado (Proyecto Estado de la Nación. Informe 10, p. 155).

Estos planteamientos significaron un sistemático cuestionamiento a lo público y, entre tanto, una redefinición de las funciones económicas y sociales del Estado, coherentes con los postulados y principios que pregonaban los llamados defensores del neoliberalismo en toda América Latina.

En el ámbito cultural y social, estos planteamientos estuvieron dirigidos para modificar la concepción histórica de la ciudadanía con respecto al Estado y a cambiar de la concepción paternalista y de Estado de bienestar a la de "Estado regulador". Este intento tendrá consecuencias en la manera cómo se va configurando el papel del Estado, respecto a la educación superior costarricense ${ }^{3}$.

\section{Del cuestionamiento de lo público al control de la calidad en la educación superior}

\subsection{Factores que propician que se hable de acreditación}

Las nuevas condiciones requeridas por el estilo de desarrollo, les demandan a las universidades estatales un replanteamiento de sus relaciones con la sociedad y con el Estado. Como consecuencias directas del nuevo papel estatal y de la liberalización comercial del país, se ubican la proliferación cuantitativa de las instituciones de educación superior y la acentuación del debate en torno al tema del financiamiento de la educación estatal. Estos dos resultados se exponen seguidamente, ya que constituyen factores determinantes que delinearon el impacto que la reforma estatal tuvo en el sector educativo.

\footnotetext{
${ }^{3}$ Para ampliar sobre este tema véase: Vega, M. (1996). Cambios en la sociedad costarricense en las décadas de los ochenta y noventa.
} 


\subsubsection{Proliferación cuantitativa de instituciones privadas de educación superior y} algunos de sus efectos más notorios

El período que comprende entre 1981 y el 2000, es el de mayor expansión de las instituciones privadas de educación superior en Costa Rica, denominadas también universidades privadas, tanto en cuanto a creación de nuevos centros privados, como en la absorción de la matrícula y expansión por áreas de estudio. Esta expansión reconfigura de manera significativa el sistema de la educación superior costarricense, colocando nuevos desafíos y abriendo el debate en torno a los argumentos que promuevan una mayor calidad y mejores condiciones "competitivas" para las universidades estatales.

Se destaca en este aspecto, el hecho de que la educación superior deja de ser competencia exclusiva del Estado costarricense, ya que se redefinen algunas de sus principales funciones redistributivas en la sociedad. Dentro de la liberalización de funciones y actividades económicas, la educación superior se reconfiguró, sobre todo en la década de los noventa, como un negocio más para la iniciativa privada. Es así cómo el Estado pierde su presencia, casi exclusiva hasta entonces, en el ámbito de la educación superior (Vega, 1996, pp.138-139).

Los datos cuantitativos suministrados por el investigador Ángel Ruiz (2001a, pp. 39-40) son claros: hasta el año 1985 la Universidad Autónoma de Centro América era la única universidad privada del país. Entre 1985 y 1991 se crearon siete y de 1992 al 2000, emergieron 40 universidades privadas en el contexto costarricense.

Otra manera numérica mediante la cual se puede evidenciar el impacto que la educación superior privada ha tenido en Costa Rica, se refiere a la absorción de la matrícula. En efecto, en el año 1980 las universidades estatales concentraron el 94,2\% del total de la matrícula, mientras que las universidades privadas solo recibieron el 5,8\% del total para la educación superior. Ya para el año 1991, el panorama era distinto: las universidades estatales absorbieron el $78,7 \%$ de la matrícula y las universidades privadas el $21,3 \%$ del total. Lo que significa que durante este período, la absorción de matrícula por parte de las universidades estatales, tuvo un decrecimiento del $16,5 \%$, mientras que en las privadas creció un $37,5 \%$.

En 1996, la matrícula en las universidades privadas casi se quintuplicó con el incremento de un $479 \%$, en relación con la matrícula de 1980. En la década de los ochenta, la participación 
de las universidades privadas en la absorción de la matrícula total universitaria, se vio incrementada año tras año, de un $5.8 \%$ en 1980 a un $21.3 \%$ en 1991 (Ruiz, 2001b, pp. 221223).

Durante los últimos años, no ha sido posible determinar el aumento en la matrícula en las instituciones privadas de educación superior, debido a que éstas no suministran la información ni tampoco han estado obligadas a hacerlo. Para 1998, el Quinto Informe del Estado de la Nación señalaba precisamente, como un gran reto para la educación superior, que debía generarse un sistema de estadísticas de las universidades privadas, similar al que ha implementado el Consejo Nacional de Rectores (CONARE) para las universidades estatales (Proyecto Estado de la Nación. Informe 5, 1998, p. 84).

Otro hecho fundamental de la proliferación de la oferta de educación superior privada, es el otorgamiento de títulos. Ya no será solo el Estado quien los confiera, sino que el mercado se encarga de una oferta de títulos que satisface todos los gustos.

En 1997, el Proyecto Estado de la Nación, en su cuarto informe, dedicó una sección al incremento del número de diplomas otorgados por las casas de enseñanza superior y confirmó la tendencia hacia la disminución de las instituciones estatales de educación superior en el otorgamiento de diplomas, tal y cómo se venía observando desde 1990. En ese último año, las universidades estatales otorgaron el $77.6 \%$ del total de diplomas, mientras que siete años después, el porcentaje disminuyó a un 52\% (Proyecto Estado de la Nación. Informe 4, 1998, p.74).

En 1990, el total de títulos entregados por las instituciones de educación superior en su conjunto, fue de 7.254 , de los cuales 5.629 correspondieron a las universidades estatales y 1.625 a las instituciones privadas de educación superior. En el año 2003, estos datos cambian drásticamente, ya que de 25.710 títulos, las cuatro universidades estatales entregaron 10.507 en total, contra 15.203 de las universidades privadas (Proyecto Estado de la Nación. Informe 10, 2004, p. 407).

El resquebrajamiento de la hegemonía estatal, es aún más notorio, si se analizan los datos relativos al postgrado. En 1990, las universidades estatales otorgaron 52 títulos de 
maestría; y 1.030 en el 2003. Por su parte, las universidades privadas pasaron de 2 títulos de maestría en 1991 a 1.297 en el 2003 (Proyecto Estado de la Nación. Informe 10, p. 407).

De este modo, se va reconfigurando el panorama nacional en el área de la formación superior, en donde el Estado deja de ser el único que otorga diplomas universitarios, ya que las instituciones privadas de educación superior van asumiendo ese papel, cada vez con mayor fuerza.

\subsubsection{Financiamiento a la educación superior estatal}

El tema del financiamiento de las universidades estatales estuvo siempre en la discusión pública y las propuestas para restringir el financiamiento a la educación superior por parte del Estado, se tornaron cada vez más fuertes.

Como bien lo señala Olimpia López (1999), en los noventa, continuaron los cuestionamientos a la eficiencia de la educación superior estatal y, las negociaciones para la obtención del presupuesto, alcanzaron niveles de enfrentamiento, tanto entre el entonces presidente Calderón Fournier y su Ministro de Hacienda, Thelmo Vargas, como entre éstos y representantes de la sociedad civil, como universitarios, docentes y sindicatos. ${ }^{4}$

Para entonces, las tesis que favorecían el financiamiento de la educación básica en contra de la superior, pregonadas a su vez por organismos financieros internacionales de gran influencia en el país, correspondían plenamente con corrientes que abogaban por un Estado que se desprendiera de su relación con la educación superior, la cual se visualizaba como elitista y por ende no como una prioridad para un país pobre como Costa Rica.

De esta manera, las políticas de reducción del gasto público y del aparato del Estado, jugaron un papel significativo en la modificación de la educación superior en Costa Rica. De acuerdo con Ángel Ruiz (2001a, p. 62), el estancamiento o contracción de los presupuestos para las universidades estatales, impidió el crecimiento institucional y de su matrícula, y

\footnotetext{
${ }^{4}$ En este sentido, es rescatable la discusión pública sobre el carácter redistributivo del financiamiento a la educación superior, entre el ex ministro de Hacienda, Thelmo Vargas y el académico, Miguel Gutiérrez Saxe por el diario La República en el año 1994.
} 
favoreció, entre otras cosas, la vertiginosa expansión cuantitativa de las instituciones privadas de educación superior, sobre todo en la década de los noventa.

Ruiz relaciona estos cambios con el estilo de desarrollo que se está delineando en el país, al señalar que:

El estilo de desarrollo en construcción ha planteado dejar en manos de la iniciativa privada un mayor número de espacios de la actividad social y concentrar los del Estado solo en ciertas acciones. Existen dentro de este escenario algunos elementos ideológicos y políticos que llevan a extremos los límites para el Estado y la sociedad civil, por ejemplo, la formación de profesionales ha sido asumida en este estilo más como un beneficio individual, y entonces privado, que como un interés público. (2001a, p. 63)

\section{Cuándo se empieza a hablar de controlar la calidad de las universidades?}

\section{1 "Medir" la calidad}

En el contexto de los programas de ajuste estructural y estabilización económica- como consecuencia de la crisis del estilo de desarrollo- se empieza a cuestionar no solo la calidad de los procesos universitarios, sino también se inician la preocupación y las discusiones acerca de cómo se puede evaluar la calidad de la educación superior.

Esta preocupación toma especial relevancia por una razón particular: las restricciones en el financiamiento público se asociaron a percepciones sobre la baja calidad y pertinencia de la educación superior. Esta discusión toma un tono singular, según Tünnerman (1998, p. 83), en función de los fenómenos de globalización y competitividad internacional, ya que se requiere formar profesionales de alta calificación para que puedan insertarse en el mercado.

Se señalan varios aspectos que incidieron en que a la educación superior se le cuestionara la calidad de sus servicios. Como bien lo apunta Olimpia López (1999, p. 18), antes, en el ámbito académico se hablaba de excelencia; luego se empieza a hablar de calidad, pero vinculada a los conceptos de eficiencia, eficacia y evaluación. Estos temas, agrega, adquieren relevancia en el marco de las crisis presupuestarias, lo que aunado a los cuestionamientos en torno al uso de los recursos estatales y los problemas de gestión de las universidades, favoreció el planteamiento de la exigencia de rendir cuentas a la sociedad sobre la utilización de los fondos estatales. 
Por otra parte, diversos cambios sociales han favorecido la irrupción de una ciudadanía más observante del uso de los recursos públicos. En este sentido, Rollin Kent, citado por Carlos Tünnerman, indica que

el debate actual sobre evaluación y calidad marca un viraje radical. A diferencia de décadas pasadas, ahora encontramos una sociedad que critica a la universidad, una universidad que debe rendir cuentas frente a públicos externos, y un sistema de educación superior donde actores tradicionalmente excluidos (bajo el concepto de autonomía) ahora son copartícipes o hasta protagonistas del cambio. (Tünnerman, 1998, p.84)

Adicionalmente, los organismos internacionales como el BM y la UNESCO, manifiestan también la importancia de que se construya un paradigma de calidad. El BM propone la definición de políticas en procura de la calidad, la equidad y la pertinencia. En sus análisis sobre la situación de la educación superior, concluye señalando el interés internacional en definir parámetros y modelos de evaluación, acreditación y determinación de la eficiencia y eficacia (López, 1999, p. 8-9).

Así, dentro del modelo de reducción de lo público, en donde parte de la educación superior se convierte en respuesta a la demanda y la oferta que indica el mercado, se empieza a perfilar la necesidad de determinar la calidad de las instituciones de educación superior y de las carreras que ofrecen. De este modo, se proponen diversos modelos para "medir" la calidad de las universidades, de sus programas y carreras. Al respecto Díaz Barriga (1995) argumenta que las políticas educativas se empezaron a apoyar en nuevos conceptos como: excelencia académica, calidad de la educación, eficiencia y desarrollo con equidad. Según el autor, lo que se trata de reducir es el gasto público, lo cual comporta el desfinanciamiento de la educación ahí donde ésta se ve no como inversión, sino como gasto (Díaz, 1995, p.38).

Díaz Barriga sostiene que la educación, desde esta perspectiva neoliberal, no tiene que responder a un problema de justicia social, sino de eficiencia social, ya que, dentro del modelo liberal, lo que se requiere es preparar profesionales para la industrialización del país y gestionar la Universidad, mediante modelos administrativos gerenciales que permitan el desplazamiento de la estructura académica tradicional. Paralelamente a este proceso, se va modificando un conjunto de concepciones sobre la educación superior. Como indicadores 
de estas transformaciones, el autor señala la utilización, en el ámbito de la educación superior, de un lenguaje de genealogía fabril, al generalizarse ahora el uso de conceptos tales como el de calidad de la educación, eficiencia y excelencia académica.

En general, en América Latina el debate reciente en torno a la búsqueda de la calidad en la educación superior universitaria, se asocia a los cambios sociales que motiva la nueva proyección del Estado, ya que no regula la totalidad de la oferta educativa de educación superior, ni es el único responsable de la calidad de los servicios sociales y económicos. También el debate es una respuesta a la tendencia de disminuir la inversión pública, lo que ha conducido, en cierta forma, a la necesidad de buscar criterios para la asignación de fondos públicos, entre las instituciones de educación superior e, incluso, en el interior de ellas mismas.

\subsection{La acreditación como propuesta de las universidades estatales}

Desde inicios de la década de los noventa se debate con mayor intensidad, en las esferas universitarias, el tema de la acreditación de las carreras ofrecidas por las instituciones de educación superior.

Según Camacho Monge (2001, pp. 92-93), el boom de la acreditación obedece a varias transformaciones sociales, entre las que se encuentran la privatización de lo público, la desregulación de las actividades humanas, el desmantelamiento de sectores estatales y el interés por deslegitimar al Estado, como el ente encargado de dar garantía de la calidad de la enseñanza y de la idoneidad profesional de los graduados. Según el autor, el problema no es el dilema entre universidades públicas y privadas, sino las orientaciones de mercado que tienen las universidades privadas. Por esta razón señala que era necesario buscar un mecanismo privado, desregulado y no estatal, que paliara el problema.

Otros autores, como es el caso de Aura Barrantes (2001, p. 79), consideran que la proliferación de universidades privadas, ha inquietado mucho al Gobierno, a la opinión pública y al Consejo Nacional de Rectores (CONARE), por lo que éste último, "dada la necesidad de garantizar la calidad de la educación superior, promueve la creación de una entidad independiente que coadyuve al respecto". 
En este contexto, diversas fuerzas internas y externas favorecen la creación del Sistema Nacional de Acreditación de la Educación Superior (SINAES). La iniciativa para establecer un mecanismo de acreditación para carreras universitarias en Costa Rica provino del CONARE, el cual está conformado precisamente por las personas rectoras de las universidades estatales.

Los orígenes de esta propuesta se remontan al año 1992, cuando el CONARE elaboró un documento titulado "Sistema de acreditación de instituciones, carreras y programas de educación superior. Una propuesta de organización". Este documento de 17 páginas, que fue también revisado y modificado por las Vicerrectorías de Docencia de las universidades estatales, constituyó la base para la futura creación del SINAES.

En el documento del CONARE, elaborado por la Oficina de Planificación de la Educación Superior (OPES), se deja claro que, de acuerdo con la experiencia internacional, en materia de acreditación, los sistemas con una administración no gubernamental, son más flexibles y más eficientes (CONARE, 1992, p. 1).

El propósito de la acreditación se plantea en ese estudio, como el "otorgar información fidedigna acerca de las instituciones educativas, de las carreras y de los programas acreditados", y se presenta a la acreditación como "una opción para ordenar la educación superior del país" (CONARE, 1992, p. 2).

En consonancia con la necesidad de ordenar la educación superior, la proliferación cuantitativa de instituciones privadas de educación superior y la disminución del financiamiento estatal dirigido a este sector educativo, fueron factores que contribuyeron, en gran medida, a que las autoridades universitarias estatales, buscaran diversas perspectivas y soluciones, internas y externas, tendientes a evaluar la acción universitaria, sus procesos y sus productos, entendidos éstos como su producción académica, su proyección y acción social y sus personas egresadas y graduadas; y que se estableciera, así mismo, que se iba a utilizar el criterio de calidad para diferenciar a las instituciones de educación superior. De este modo, la discusión se centró en torno a la preocupación por la calidad de la educación, y sobre quién podría garantizar la calidad de la educación superior en Costa Rica.

En esta búsqueda, los órganos rectores de las universidades estatales reconocieron la importancia de establecer mecanismos de autoevaluación y de evaluación externa que 
pudieran dar fe pública de la calidad académica de las carreras y programas de las universidades de la educación superior costarricense. Dentro de este contexto, surgieron, de manera central, el tema y el debate sobre la calidad y, de manera particular, la acreditación en la educación superior.

El tema de la acreditación no es nuevo. En el ámbito mundial y, específicamente en el latinoamericano, la acreditación de carreras o instituciones cuenta con un apoyo decisivo de las mismas universidades y de los Estados. En Costa Rica, la acreditación surgió como un mecanismo defensivo de las autoridades universitarias estatales, con el cual se pretendía revertir el desbalance suscitado en la oferta universitaria, como resultado de los aspectos del estilo de desarrollo, los cuales favorecen la desregulación del mercado.

Los objetivos de la acreditación quedan claros en la Ley 8256 que da origen al SINAES, al expresar que los procesos de acreditación deben garantizar continuamente la calidad de las carreras y de los planes y programas ofrecidos por las instituciones de educación superior. Además, expresa que el proceso de acreditación tendrá como prioridad, garantizar la calidad de los planes, las carreras y los programas que ofrecen las instituciones y se caracterizará por ser un generador de mejoramiento voluntario, participativo, abierto, endógeno, confiable y periódico en el marco del diseño de un modelo que deberá atender los estándares internacionales utilizados en estos procesos (Asamblea Legislativa de Costa Rica, Decreto Legislativo 8256).

Según el SINAES, el Estado cumple dos papeles diferentes con la acreditación: primero, informar a la sociedad; segundo, reconocer públicamente el logro de determinados niveles de calidad. A la vez, la acreditación implica mejorar la calidad de los programas y carreras que ofrecen las instituciones universitarias, y garantizar públicamente la calidad de estos.

De esta manera, la acreditación tiene como propósito identificar, con carácter oficial, las carreras y los programas universitarios que cumplan los requisitos de calidad que establezca el SINAES, para mejorar con ello la calidad de los programas y las carreras ofrecidas por las instituciones universitarias públicas y privadas, y garantizar públicamente su calidad. 


\section{3 ¿La calidad paga?}

Dentro de la lógica neoliberal de organización de la educación superior, las consecuencias de la acreditación de programas y carreras parecen obedecer a diferentes motivos, según se trate de universidades públicas o privadas.

Para algunas de las instituciones privadas de educación superior, la acreditación de sus carreras sirve como negocio y factor de mercadeo, ya que la certificación pública de que se cuenta con una carrera acreditada, atrae a las personas desde el punto de vista de la oferta y la demanda de opciones de educación superior. Por otro lado, y teniendo en cuenta el estilo de organización y la capacidad de absorción de matrícula de las instituciones de educación superior estatales, pareciera ser que a las universidades privadas no les interesa competir con las universidades estatales, en cuanto a la captación de estudiantes, dado que estas últimas tienen una capacidad de absorción de matrícula que ya alcanzó los límites máximos en relación con su infraestructura, y con los recursos económicos de que disponen.

Es así cómo la acreditación, vista como factor de mercadeo por las universidades privadas, se presenta como un elemento que favorece la competencia entre ellas, de manera tal que la acreditación de la calidad es una inversión que les permite consolidarse en el mercado.

Para las universidades estatales, la acreditación de carreras se enmarca dentro de la lógica de rendición de cuentas propia del estilo de desarrollo, donde el Estado privilegia sus funciones supervisoras-controladoras por sobre las ejecutoras. Dentro de este razonamiento, el Estado les asigna fondos públicos a las universidades estatales y luego cuestiona y espera informes acerca de cómo se están utilizando. Este control no se aplica a las universidades privadas.

En términos generales, la acreditación significa para las universidades estatales, un acercamiento al proceso de rendir cuentas ante la sociedad sobre la utilización de los recursos públicos. Por otro lado, para las instituciones privadas de enseñanza superior, la acreditación aparece como un mecanismo de legitimación con efectos concretos en el reconocimiento social, al formar parte del mismo sistema de control que las universidades estatales y con sus mismos estándares. 


\section{Comentarios finales}

La reconfiguración del sistema de educación superior costarricense, se plantea en el contexto de un estilo de desarrollo neoliberal, en donde la acreditación de carreras universitarias, y la consecuente definición de la política pública, tendiente al establecimiento del órgano acreditador nacional, el SINAES, responde directamente a la lógica de un Estado que delega, en otras instancias, su papel ejecutor e interventor directo, mientras que las fuerzas del mercado se fortalecen y definen aspectos importantes de la organización y oferta del sistema de educación superior.

En efecto, las características del modelo neoliberal exacerbaron, en alguna medida, ciertas tendencias que se venían observando desde los años ochenta, tales como el incremento de la oferta de educación superior y los problemas para conseguir el financiamiento estatal para las universidades. Esto, aunado a las demandas sociales de rendición de cuentas y de petición de que las universidades demostraran la calidad de sus productos y sus procesos, hace que se visualice a la acreditación, como una respuesta de las autoridades de la educación superior a la nueva configuración del sistema de educación superior, acorde con las tendencias nacionales e internacionales.

Vista la acreditación como verificación pública de la calidad de las carreras y de los planes y programas ofrecidos por las instituciones de educación superior, ésta se perfila como un instrumento que permite diferenciar la oferta educativa del país y obtener también retribuciones diferentes, por parte de la sociedad que demanda sus servicios.

Desde los orígenes mismos de la creación del SINAES, en donde las universidades estatales desempeñaron un rol decisivo, la acreditación de carreras implica recurrir a criterios de calidad frente a la necesidad de rendir cuentas ante la sociedad. Con esto se pretendía deslegitimar, de alguna manera, a muchas de las universidades privadas recientemente fundadas, aduciendo que estas no atendían a criterios de calidad en su gestión ni en su oferta educativa.

Sin embargo, vista como un factor de mercadeo, la acreditación de carreras y programas de educación superior, posibilita que algunas de las instituciones de enseñanza superior, cuya finalidad es lucrar mediante la oferta y demanda de formación universitaria, puedan recurrir 
al mismo sistema ideado y aplicado a las universidades estatales para acreditarse con los mismos criterios y estándares que estas utilizan.

Finalmente, es importante dejar claro que las discusiones en torno a la calidad de la oferta educativa universitaria, implica realizar antes un proceso de reflexión y definición de lo que debe ser una Universidad, lo que ésta debe ofrecer a la sociedad y cómo debe contribuir a la construcción de sociedades más democráticas y equitativas. Sin esta reflexión previa, quedarían varias interrogantes: ¿qué se está acreditando y la calidad de qué? ¿Se está acreditando lo que siempre se ha venido haciendo? ¿Se están acreditando programas y carreras pertinentes, de acuerdo con las necesidades del país? Y, si esto es así, ¿a cuáles necesidades concretas se trata y a las necesidades de qué país o de qué parte del país? ¿Se están acreditando alternativas de educación superior realmente relevantes y acordes con el concepto de desarrollo que favorezca una reinserción favorable de nuestro país en el sistema mundial? ¿Se están acreditando carreras que impulsan el equilibrio ecológico, por ejemplo?

Previo al sello de acreditación que otorga la agencia externa a la universidad, se desarrolla un proceso de autoevaluación, al final del cual las carreras se comprometen a revisar a fondo, los aspectos en los cuales la evaluación encontró deficiencias. El plan de mejoramiento propuesto se asume como un compromiso. Ahí reside gran parte del reto de la acreditación para universidades, tanto estatales como privadas: ¿se basan esos planes únicamente en mejoras de infraestructura, equipos, gestión, o por el contrario, suponen replanteamientos que van más allá de una visión reduccionista y estática de la acreditación? El plan de mejoramiento debería ser la esencia de la acreditación y la posterior reacreditación la prueba de fuego de las carreras, a las cuales se les ha certificado la calidad.

Vale entonces preguntarse, si están dispuestas, tanto las carreras de las instituciones privadas de educación superior como estatales, a continuar el proceso y buscar la reacreditación. ¿Van a seguir apostando a la calidad de sus carreras? ¿Continuará en las universidades privadas, el esfuerzo y la inversión en la calidad como manera de legitimarse, distinguirse y ganar mercado? ¿Cuál será el papel de la agencia acreditadora nacional en la reacreditación de las carreras? ¿Qué harán las autoridades universitarias en la definición del concepto de calidad y pertinencia subyacente en los procesos de reacreditaciòn? 


\section{REFERENCIAS}

Asamblea Legislativa de la República de Costa Rica. (2002). Decreto Legislativo 8256. Ley del Sistema Nacional de Acreditación de la Educación Superior (SINAES). San José, Costa Rica: La Asamblea.

Barrantes, A. (2001). Autoevaluación y acreditación de las carreras de la Universidad de Costa Rica. Revista de Ciencias Sociales (92-93): 2001, 77-91.

Camacho, D. (2001). Los sesgos en los procesos de evaluación y acreditación. Revista de Ciencias Sociales (92-93): 2001, 7-11.

Cervantes, F. (1999). Propuesta de un mecanismo para establecer criterios de distribución del fondo especial de la educación superior universitaria estatal. Revista de Educación 23 (1): 1999, 7-45.

Comisión Nacional de Préstamos para la Educación, CONAPE. (s.f.). Comisión Nacional de Préstamos para la Educación. 25 Aniversario. San José: CONAPE.

Comisión Nacional de Rectores, CONARE. (1992). Sistema de acreditación de instituciones, carreras y programas de educación superior. Una propuesta de organización. San José: Comisión interinstitucional de Vicerrectores de Docencia.

Comisión Nacional de Rectores, CONARE. (1993). Convenio para la creación del Sistema Nacional de Acreditación de la Educación Superior (SINAES). Sesión 07.93.

Cruz, A. (1992). La vinculación universidad-sector productivo en Costa Rica: Una aproximación al tema. San José: Documento mimeografiado.

De Miguel, M. et al. (1994). Evaluación para la calidad de los institutos de educación secundaria. Madrid: Editorial Escuela Española, S. A.

Díaz, Á. (1995). Empleadores de universitarios. Un estudio de sus opiniones. México: Centro de Estudios sobre la Universidad, UNAM.

López, O. (1999). La universidad estatal en el contexto sociopolítico de la década de los 90. Revista de Ciencias Sociales (23): 1999, 7-22.

Martín, M. et al. (2002). Estudios de caso sobre acreditación en Colombia, Hungría, India, Filipinas y Estados Unidos: tan similares pero tan diferentes. Primer Seminario Internacional: Educación superior, calidad y acreditación. Santafé, Colombia: Consejo Nacional de Acreditación equidad y la convivencia. Plan Decenal de Educación.

Peralta, T. (1999). Calidad, evaluación y acreditación universitaria: una reflexión sobre su praxis. Revista de Ciencias Sociales. 23. (Número especial): 1999, 137-146

Programa de las Naciones Unidas para el Desarrollo (PNUD). (1999). Los retos educativos del futuro. Estado de la Educación en América Latina y el Caribe. Costa Rica: PNUD. 
Programa Estado de la Nación. (2004). Décimo Informe Estado de la Nación en Desarrollo Humano Sostenible. Costa Rica: Proyecto Estado de La Nación.

Proyecto Estado de la Nación en Desarrollo Humano Sostenible. (1998). Estado de la Nación en Desarrollo Humano Sostenible No 4. Costa Rica: Proyecto Estado de La Nación.

Proyecto Estado de la Nación en Desarrollo Humano Sostenible. (1999). Estado de la Nación en Desarrollo Humano Sostenible: un análisis amplio y objetivo sobre la Costa Rica que tenemos a partir de los indicadores más actuales. Costa Rica: Proyecto Estado de La Nación.

Proyecto Estado de la Nación en Desarrollo Humano Sostenible. (2002). Estado de la Nación en Desarrollo Humano Sostenible: Octavo Informe. Costa Rica. Proyecto Estado de La Nación.

Rovira, J. (1995). La actual coyuntura política nacional: notas para su comprensión. Contribuciones. (22). 1-56

Ruiz, A. (2001 a). La educación superior en Costa Rica. Tendencias y retos en un nuevo escenario histórico. San José: Editorial de la Universidad de Costa Rica.

Ruiz, A. (2001 b). El Destino de la educación superior en Costa Rica. El escenario Histórico del país, la educación y el papel de la Universidad. San José: Editorial de la Universidad de Costa Rica.

Ruiz, A. (2001 c). El Siglo XXI y el papel de la Universidad. Una radiografía de nuestra época y las tendencias en la educación superior San José: Editorial de la Universidad de Costa Rica.

Sistema Nacional de Acreditación de la Educación Superior (SINAES). (2000). Manual del Sistema Nacional de Acreditación de la Educación Superior. Convocatoria del año 2000. San José: SINAES.

Stiglitz, J. (2002). El malestar en la globalización. Argentina: Taurus, Alfaguara, S.A.

Tünermann, C. (1998). Transformación de la educación superior: retos y perspectivas. Costa Rica: EUNA.

Universidad de Costa Rica. Vicerrectoría de Docencia. (2001). Resolución 7042-2001. San José: Vicerrectoría de Docencia.

Universidad de Costa Rica. Consejo Universitario. (1995). Acta 4159. 29 de noviembre de 1995. Anexo 6. San José: Consejo Universitario.

Vega, M. (1996). Cambios en la sociedad costarricense en las décadas de los ochenta y noventa. Anuario de Estudios Centroamericanos. Universidad de Costa Rica 22(2): 1996, 129-146. 
Vega, M. (1984). La recomposición del bloque en el poder en Costa Rica, la política norteamericana y el Fondo Monetario Internacional (1982-1984). Coyuntura y perspectivas. Anuario de Estudios Centroamericanos. Universidad de Costa Rica. 10: 1984, 59-67. 